Check for updates

Cite this: RSC Adv., 2019, 9, 6094

\title{
Why the thin film form of a photocatalyst is better than the particulate form for direct solar-to- hydrogen conversion: a poor man's approach $\dagger$
}

\author{
Naresh Nalajala, (D) ${ }^{a}$ Kshirodra Kumar Patra, ${ }^{a}$ Pradnya A. Bharad ${ }^{a}$ \\ and Chinnakonda S. Gopinath (D)*ab
}

\begin{abstract}
We demonstrated an easy method to improve the efficiency of photocatalysts by an order of magnitude by maximizing light absorption and charge carrier diffusion. Degussa titania (P25) and Pd/P25 composite photocatalyst thin films coated over regular glass plates were prepared and evaluated for solar hydrogen production in direct sunlight with aqueous methanol. It is worth noting that only UV light present in direct sunlight ( $4 \%$ ) was absorbed by the catalysts. The hydrogen production activities of catalysts were compared for thin film and particulate forms at 1 and $25 \mathrm{mg}$ levels. The hydrogen yield values suggested that $1 \mathrm{mg}$ thin film form of Pd/P25 provided 11-12 times higher activity than $25 \mathrm{mg}$ powder form. Comparable light absorption throughout the entire thickness of photocatalyst device and better contact of nanostructures that enabled the charge diffusion and charge utilization at redox sites are the reasons for high efficiency. While solar cells require charge carriers to diffuse through long distances of microns, they are utilized locally in an ensemble of particles (of nanometres) for hydrogen generation in photocatalyst thin films; this concept was used effectively in the present work.
\end{abstract}

Received 4th December 2018

Accepted 5th February 2019

DOI: $10.1039 / \mathrm{c} 8 \mathrm{ra09982k}$

rsc.li/rsc-advances reaction with suitable combination of semiconductors and metal nanostructures is preferred as the method is truly renewable. ${ }^{10-13}$ However, $\mathrm{H}_{2}$ production from the particulate form of photocatalyst is hindered by several limitations. For example, a simple doubling of catalyst quantity from 75 to $150 \mathrm{mg}$ decreases the efficiency from 6.3 to $2.7 \%$, respectively, due to several factors. ${ }^{\mathbf{1 4}}$ Light scattering, rather than light absorption, and charge recombination are critical problems that seem to occur even for such small amounts of catalysts, which has been investigated by a number of researchers. Increasing the amount of water or aqueous solution layer thickness and stirring the aqueous suspension with catalysts can decrease the light penetration depth and light absorption. Maintaining comparable light absorption by all particles in a catalyst system at high volumes of liquid reactants is a major challenge, and this is unlikely to be achieved, especially with sunlight. ${ }^{6,15}$ This compels us to view and approach the photocatalysis problem in a vertical approach. While light harvesting principles largely remain the same, the exact working mechanism is significantly different. In solar cells, electrons with kinetic energy (due to light absorption) need to diffuse through several microns to reach the bottom conducting plate (FTO/ITO) to produce enough current. However, charge carriers need not diffuse for very long distances of microns, and they can be utilized locally in an ensemble of nanoparticles in photocatalysis since the latter occurs at the molecular level. Indeed, this arrangement is unlikely to produce more current but could be an effective approach for photocatalysis. Comparable light 
absorption by all catalyst particles that are connected locally in the presence of reactants would be the minimum requirement to test this hypothesis. This approach requires maximizing the surface area with a small amount of photocatalysts and with maximum possible light penetration and hence, comparable light absorption can be achieved. In this context, very few reports are available in the literature on producing solar $\mathrm{H}_{2}$ from water splitting using a panel-type reactor. Xiong et al. ${ }^{\mathbf{1 6}}$ described the design aspects of panel-type reactors for improved efficiency of the water splitting reaction using an $\mathrm{Rh}_{2-y} \mathrm{Cr}_{y} \mathrm{O}_{3} /\left(\mathrm{Ga}_{1-x} \mathrm{Zn}_{x}\right)\left(\mathrm{N}_{1-x} \mathrm{O}_{x}\right)$ photocatalyst on $5 \times 5 \mathrm{~cm}^{2}$ flat frosted glass plates. Schröder et al. ${ }^{17}$ reported that carbon nitride photocatalysts immobilized on a stainless steel plate can produce hydrogen in the presence of a sacrificial agent under sunlight. Furthermore, Goto et al. ${ }^{18}$ recently demonstrated the water splitting reaction without any sacrificial reagents under natural sunlight using $\mathrm{Al}$-doped $\mathrm{SrTiO}_{3}$ photocatalysts on a $1 \times$ $1 \mathrm{~m}^{2}$ panel at 0.1 bar. It is worth mentioning that the particulate matter coated as thin film panels having low efficiency $(3-5 \%)$ can economically compete ${ }^{17}$ with the high-efficiency $(\geq 10 \%)$ PEC technology; the former, which requires a small amount of material and minimum equipment, outweighs the latter having high efficiency.

The $\mathrm{TiO}_{2}$ films on glass plates have already been demonstrated to have wide applications such as in dye-sensitized solar cells (DSSC) and self-cleaning window panels. ${ }^{19-21}$ To the best of our knowledge, no report is available on titania-based materials for panel-type reactors to produce solar $\mathrm{H}_{2}$ with direct sunlight. Even though the anatase phase of $\mathrm{TiO}_{2}$ exhibits a wide bandgap ( $\sim 3.2 \mathrm{eV}$; UV-active), it is considered to be the state-of-the-art photocatalyst because of low cost, high stability and high oxidizing power of holes. ${ }^{22}$ In the present work, commercial titania (P25; $4: 1$, anatase : rutile) was employed as the semiconductor to harvest direct sunlight and Pd was used as the cocatalyst for $\mathrm{H}_{2}$ generation with aqueous methanol as the sacrificial agent. Pd/P25 and P25 were employed as the photocatalysts in both powder and panel types (thin films over plain glass plates) and the activities were compared.

\section{Results and discussion}

The digital photographs of the thin films of the photocatalysts (P25 and Pd/P25) are shown in Fig. 1. A colour difference was observed between the pristine (P25, white; Fig. 1a) and Pd/P25 (grey; Fig. 1b-d) photocatalysts; it is to be noted that only the thin film with $1.25 \times 3.75 \mathrm{~cm}^{2}$ area was evaluated for solar hydrogen production under direct sunlight in a quantitative manner. The photograph shown in Fig. 1 mainly demonstrates that large-sized films can also be prepared by the drop-casting method. The appearance of all thin films suggested that the photocatalyst is not deposited uniformly over the glass plate, and this was confirmed by FESEM analysis (shown later in Fig. 3). Nevertheless, hydrogen evolution in the direct sunlight was visible over the entire tested film surface of $2.5 \times 3.75 \mathrm{~cm}^{2}$ (see ESI-1 $\uparrow$ for $\mathrm{H}_{2}$ generation video recorded with $\left.\mathrm{Pd} / \mathrm{P} 25\right)$. Even though the film surface exhibited inhomogeneity, gaps and cracks, hydrogen generation was abundant, visible and all over the surface (see discussion later). This was attributed to the large penetration or skin depth of sunlight into the entire depth of the thin film of photocatalysts and possible internal reflection due to the mesoporous texture of titania. ${ }^{15}$ Thus, some of the important issues that can be addressed in the present thin film configuration are surface roughness and light absorption. In fact, they are prevalent issues in the design of PEC cells, where very smooth films without any cracks/gaps are crucial; otherwise, the entire charge flow is affected, thus affecting the efficiency. While charge carriers are utilized locally in an ensemble of particles in a small area for water splitting, charge carriers have to diffuse for several tens of microns in solar cells and DSSCs. This necessitates the interconnectivity of particles much more thoroughly for latter applications. Hence, surface inhomogeneity and cracks in the thin film do not hamper the reaction seriously. However, other coating techniques such as screen printing, spray coating, and the doctor blade method may provide better-quality thin films and are expected to give better results ${ }^{11,23}$ than the current results. In our earlier work, using the doctor-blade method, we prepared photoanodes $\left(\mathrm{TiO}_{2} / \mathrm{PbS} / \mathrm{CdS}\right.$ and $\left.\mathrm{Au}-\mathrm{TiO}_{2} / \mathrm{PbS} / \mathrm{CdS}\right)$ and demonstrated much higher hydrogen yield. ${ }^{11}$ Therefore, there is a possibility for the preparation of large-area titania-coated plates $\left(e . g ., 1 \times 1 \mathrm{~m}^{2}\right)$ for solar $\mathrm{H}_{2}$ production without compromising the activity.

Fig. 2 presents the physical characterizations of P25 and Pd/ P25. The structural details of photocatalysts were identified using XRD patterns (Fig. 2a). Rutile and anatase phase features were present in P25 and labelled to appropriate lattice planes; majority of the high intensity peaks were from the anatase phase. The peaks observed at $2 \theta=39$ and $\sim 46^{\circ}$ exhibited lowintensities, corresponding to $\operatorname{Pd}(111)$ and $\operatorname{Pd}(200)$ facets (inset in Fig. 2a). Fig. 2b shows the PL characteristics of photocatalysts recorded with $\lambda=310 \mathrm{~nm}$ photons. A relatively intense PL feature with pristine P25 was observed, suggesting a high recombination rate of $\mathrm{e}^{-} \mathrm{h}^{+}$pairs. Furthermore, Pd/P25 showed significant attenuation of PL emission intensity; this indicated that the electrons generated are trapped by $\mathrm{Pd}$, thus providing effective charge utilization for $\mathrm{H}_{2}$ generation.

The UV-vis absorption spectra are given in Fig. 2c; as expected, P25 and Pd/P25 showed strong absorption below $400 \mathrm{~nm}$ due to band gap excitation of predominant anatase titania. It was also observed that an increase in the background absorption of visible light for $\mathrm{Pd} / \mathrm{P} 25$ was attributed to the scattering of high-wavelength light. This observation was consistent with grey color of the catalyst. Even though rutile phase was present, there was hardly any visible-light absorption, as shown in Fig. 2c. The TEM image of the Pd nanoparticles is presented in Fig. 2d. The size of Pd nanoparticles was between 3 and $5 \mathrm{~nm}$ with random morphology. The dspacing measured from the lattice fringes was $\sim 0.23 \mathrm{~nm}$ and it corresponded to the (111) facet of Pd. It should be noted that the $\operatorname{Pd}(111)$ facet was further confirmed from XRD pattern (inset in Fig. 2a).

The surface morphology, film thickness (Fig. 3) and composition details of the thin films were obtained using FESEM with EDX set up. Fig. 3a shows that the titania nanostructures are in good contact with each other. This is probably 


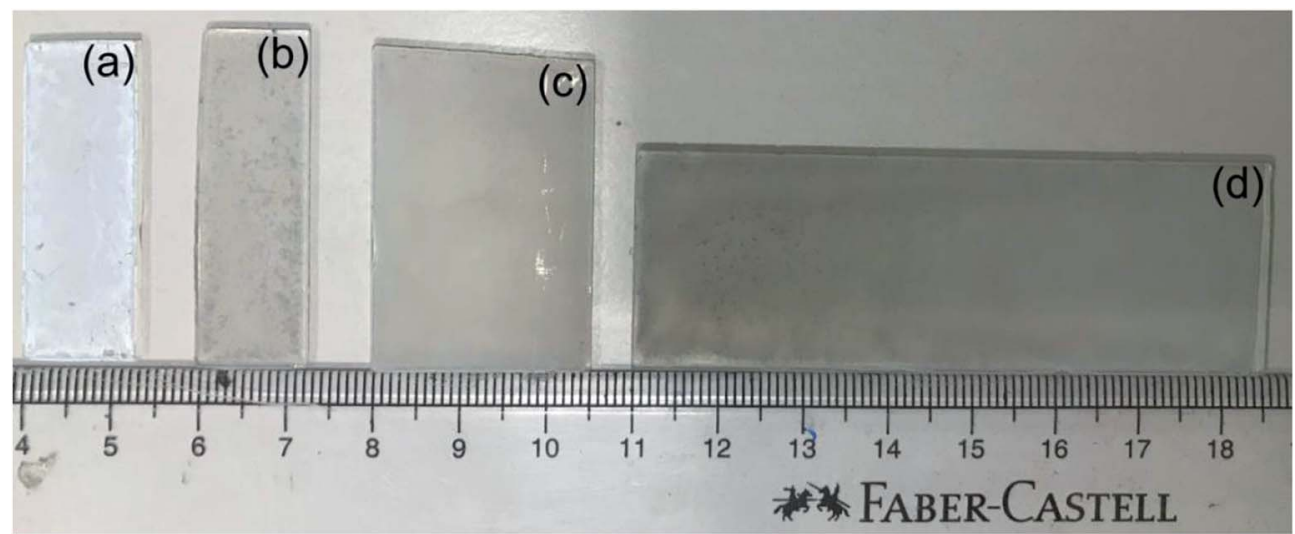

Fig. 1 Photographs of thin films of P25 of (a) $1.25 \times 3.75$ and Pd/P25 of (b) $1.25 \times 3.85$, (c) $2.5 \times 3.75$, and (d) $2.5 \times 7.5 \mathrm{~cm}^{2}$.

one reason for better solar hydrogen activity compared to that of the powder form catalyst, where dispersion is a major issue. The cracks/gaps on the films were clearly visible (inset in Fig. 3a), suggesting that the drop-cast methodology needs to be further improved to obtain better-quality films. Even though inhomogeneity persisted on the thin film surface, excellent hydrogen generation was observed from the entire thin film (see video in ESI-1†). The EDX analysis of the Pd/P25 films indicated the composition to be $0.91 / 56.47 / 42.63 \mathrm{wt} \%(\mathrm{Pd} / \mathrm{Ti} / \mathrm{O})$ and it was the same as the nominal input values. The average thickness of the film was measured to be $8 \mu \mathrm{m}$ and it varied between 7.5 and 8.5 $\mu \mathrm{m}$ throughout the film (Fig. 3b).

The hydrogen production activities of the catalysts in powder and thin film forms were evaluated under direct sunlight in the water/methanol mixture, and the results are shown in Fig. 4. The photocatalysts of powder form were evaluated by following
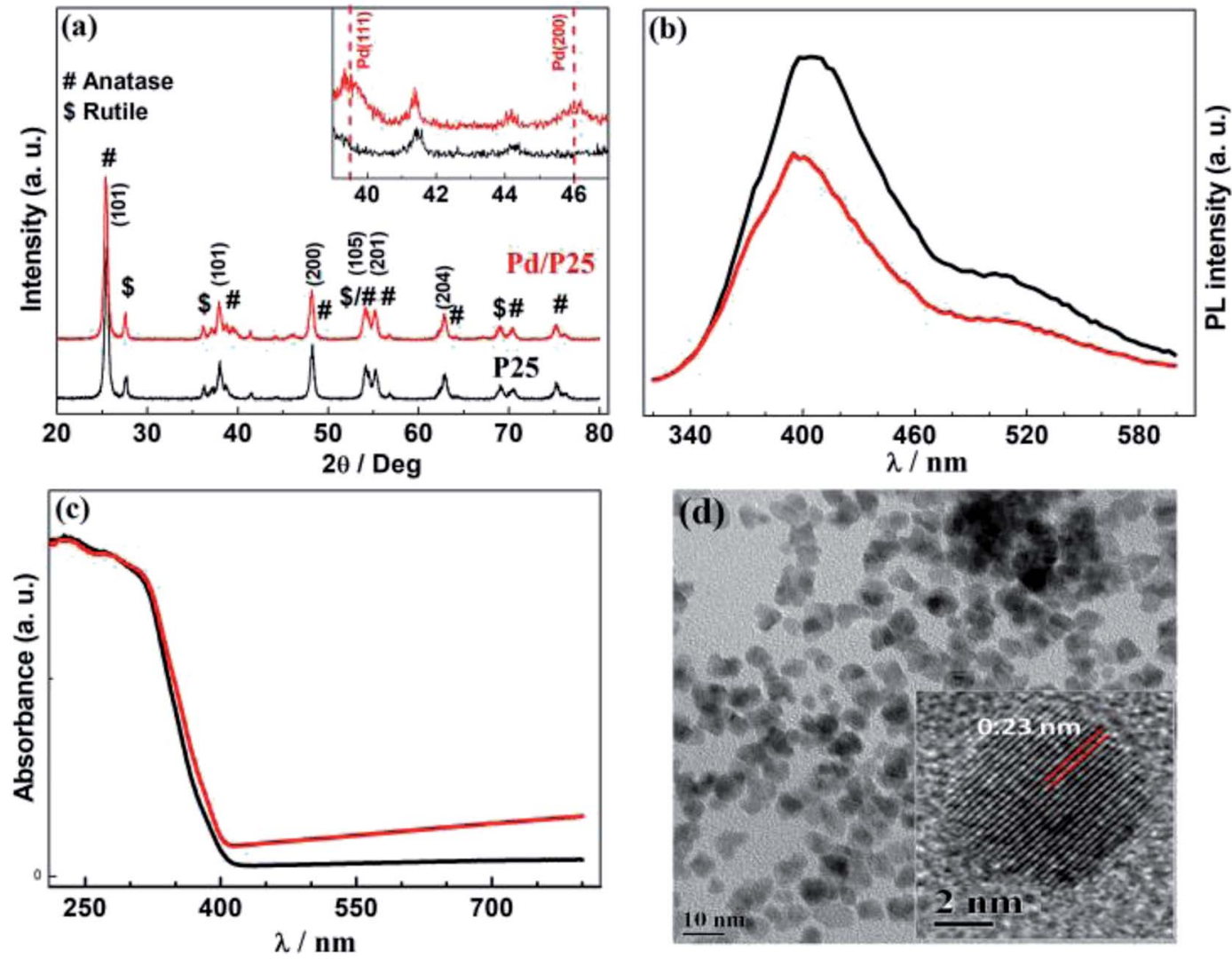

Fig. 2 Physical and spectral characterization of P25 and Pd/P25 composite: (a) XRD patterns; the inset shows the enlarged view of Pd features. (b) Photoluminescence spectra, (c) UV-vis absorption spectra, and (d) TEM image of Pd nanoparticles; the inset shows the high-resolution image of Pd nanoparticles. 

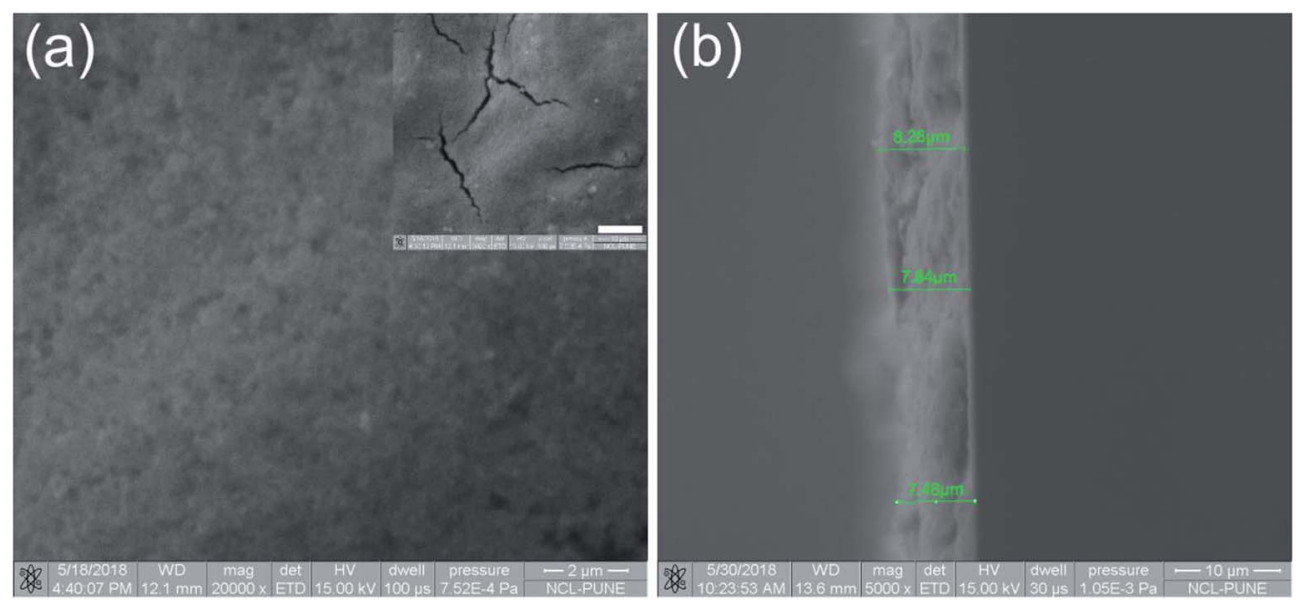

Fig. 3 FESEM images of Pd/P25 thin films over a glass plate for (a) surface morphology at a scale bar of $2 \mu \mathrm{m}$, and (b) cross sectional view of a freshly cleaved thin film at a scale bar of $10 \mu \mathrm{m}$. Inset in (a) shows the cracks present on the film surface at a scale bar of $10 \mu \mathrm{m}$.

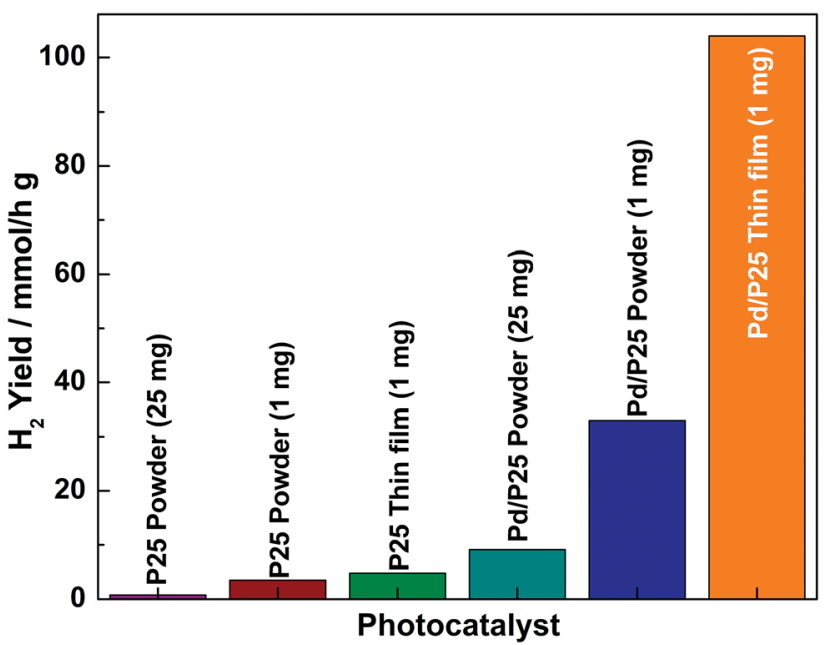

Fig. 4 Photocatalytic hydrogen production activities of P25 and Pd/ P25: P25 powder (25 mg), P25 powder (1 mg), P25 thin film (1 mg), Pd/ P25 powder (25 mg), Pd/P25 powder (1 mg), and Pd/P25 thin film (1 $\mathrm{mg})$.

procedures reported in the literature..$^{2,13}$ Some of the points derived from the results are worth highlighting: (a) the hydrogen production activities of powder catalysts (P25 and $\mathrm{Pd} / \mathrm{P} 25)$ were low compared to those of the corresponding thin film form catalysts even though the catalyst remained the same. (b) A small (1 mg) amount of catalyst in powder form provided a large amount of hydrogen, while a large amount of catalyst $(25 \mathrm{mg}$ ) led to a lower hydrogen yield, indicating a reverse correlation between the content and the rate. (c) It was observed that P25 in the particulate form exhibited the lowest activity $\left(0.76 \mathrm{mmol} \mathrm{h}^{-1} \mathrm{~g}^{-1}\right)$ compared to its corresponding Pd/P25 composite counterpart (9.11 $\mathrm{mmol} \mathrm{h}^{-1} \mathrm{~g}^{-1}$ ) tested with $25 \mathrm{mg}$ photocatalyst. (d) The most interesting observation was that $1 \mathrm{mg}$ of powder form of Pd/P25 catalyst coated over $4.69 \mathrm{~cm}^{2}$ showed the highest hydrogen production value of $104 \mathrm{mmol} \mathrm{h}^{-1} \mathrm{~g}^{-1}$; compared to the results obtained with $25 \mathrm{mg}$ Pd/P25 powder, the hydrogen yield was 11-12 times higher for the thin film form with $1 \mathrm{mg}$ material. However, it is reasonable to compare the activities and quantum yields of different samples (thin film and powder) at the same loading $(1 \mathrm{mg})$, and three times higher activity was observed with the thin film compared to that with the powder form. This observation fully supported the proposed hypothesis: a minimum amount of material with maximum light exposure is, indeed, beneficial towards increasing light harvesting and consequently the quantum yield. (e) The present results suggest that it is important to explore the optimum amount of a catalyst coated over an optimum area and thickness for the best possible results. Furthermore, this demonstrates that the phototcatalyst on the fixed substrate provides efficient photocatalytic reaction kinetics than that of powder form in solution. This maximized the utilisation of the surface area of $\mathrm{Pd}$ as well as P25. Among the catalysts, Pd/P25 exhibited better activity compared to pristine P25, suggesting that Pd acted as a better co-catalyst to trap the electrons and increase $\mathrm{H}_{2}$ yield. (f) It should be noted that light absorption by anatase titania is only from UV, which is fully supported by UV-Vis absorption spectra (Fig. 2c). Large $\mathrm{H}_{2}$ generation indicated the necessity to exploit $\sim 4 \%$ UV present in the sunlight. While powder form suffers from recombination, thin films can overcome the same problem to a significant extent. (h) Pd/P25 evaluated over four days in direct sunlight for about $25 \mathrm{~h}$ (data not shown) demonstrated the sustainable activity and the stability of the thin film. (i) A catalyst from other sources with uniform particle size also showed very similar variation in activity from powder to thin film form. (j) Assuming a linear change in activity for larger size of a thin film, an increase in scale up to $4.7 \mathrm{~m}^{2}$ with $1 \mathrm{~g} \mathrm{Pd} / \mathrm{P} 25$ thin film catalyst would lead to $2.33 \mathrm{~L} \mathrm{~h}^{-1} \mathrm{H}_{2}$ in direct sunlight. This is probably the best value reported in the literature so far. This highest value is due to exclusive UV light absorption from sunlight. Even if 50\% reduction in $\mathrm{H}_{2}$ yield occurs due to scale-up issues, it would be higher than any reported value till date. 
A set of reference experiments was conducted with 1 and $25 \mathrm{mg}$ of powder $\mathrm{Pd} / \mathrm{TiO}_{2}$ under the same conditions as that of other experiments. However, the solution was not stirred during illumination, mainly to simulate the thin film measurement conditions. No measurable $\mathrm{H}_{2}$ generation was observed with the $25 \mathrm{mg}$ batch, while $1 \mathrm{mg}$ batch showed $2.1 \mathrm{mmol} \mathrm{h}^{-1} \mathrm{~g}^{-1}$. This suggests that stirring improves $\mathrm{H}_{2}$ generation with minimum amount of catalyst mostly due to better exposure to light; however, the activity is far below the level of thin film made with $1 \mathrm{mg}$ or powder under stirring. This indicated that the interparticle connectivity in the short range is important for charge carrier utilisation for water splitting. The thin film made with $2 \mathrm{mg}(\sim 14 \mu \mathrm{m}$ thick) showed a mere $10 \%$ increase in activity than that made with $1 \mathrm{mg}$. However, the thin film made with $0.5 \mathrm{mg}$ (4.5-5 $\mu \mathrm{m}$ thick) displayed $40 \%$ decrease in activity compared with that made with $1 \mathrm{mg}$. In fact, many reports suggest that a good-quality thin film with $8-12 \mu \mathrm{m}$ thickness is required for the optimum performance of DSSCs. This indicates that the thickness of films reported with $1 \mathrm{mg}(8 \mu \mathrm{m})$ is just appropriate for the best solar harvesting. Thickness of more than $8-12 \mu \mathrm{m}$ led to no (or minimum) light absorption by the bottommost layers, while less than $8 \mu \mathrm{m}$ thickness led to insufficient thickness of the photocatalyst layer, leading to lower amount of light absorption and hence lower activity. Chronoamperometry measurements in one sun conditions at no applied potential were obtained on similar quality thin films made on an FTO plate in a three-electrode assembly in $0.5 \mathrm{M}$ $\mathrm{KOH}$ electrolyte. ${ }^{2}$ No measurable current was observed with P25; however, with Pd/P25, a marginal amount of photocurrent $\left(0.7-0.8 \mu \mathrm{A} \mathrm{cm}^{-2}\right)$ was observed, indicating the large recombination of charge carriers due to several factors such as cracks in thin films. Indeed this device is not good for photocurrent generation, as we envisaged.

The AQY values of different catalysts are given in Table 1 . The results indicate that the pristine titania (P25)-based catalyst exhibited negligible AQY compared to $\mathrm{Pd} / \mathrm{TiO}_{2}$. Among the catalysts tested, thin film-based Pd/P25 showed the highest AQY for solar hydrogen generation under direct sunlight. Moreover, the present efforts motivated us to search for the design of better-quality thin films for cost-effective solar $\mathrm{H}_{2}$ production towards large scale by the optimization of various experimental parameters. Although the present drop-casting method of the preparation of thin films may not afford stability for a very long time, thin films prepared by other methods with comparable thicknesses are expected to show similar or better activities.

Table 1 AQY of P25 and Pd/P25 in particulate and thin film forms for solar hydrogen generation

\begin{tabular}{ll}
\hline Catalyst (weight) & AQY $(\%)$ \\
\hline P25 powder $(25 \mathrm{mg})$ & 0.007 \\
P25 powder $(1 \mathrm{mg})$ & 0.032 \\
P25 thin film $(1 \mathrm{mg})$ & 0.044 \\
Pd/P25 powder $(25 \mathrm{mg})$ & 0.084 \\
Pd/P25 thin film $(1 \mathrm{mg})$ & 0.96 \\
Pd/P25 powder $(1 \mathrm{mg})$ & 0.31
\end{tabular}

\section{Conclusions}

In the present work, titania-based thin films over a glass plate were prepared by a simple drop-casting method and evaluated for solar hydrogen production under direct sunlight. The activity of catalysts was evaluated in powder and thin film forms; the results obtained indicated that the thin film form outperformed the particulate form by an order of magnitude. The possible reason for larger solar hydrogen production is the better light absorption by the maximum amount of catalyst due to maximization of surface area utilization. Unlike the observations for solar cells, charge carriers generated were consumed effectively within an ensemble of particles in a very small area, and hydrogen production from all over the thin film supported this conclusion directly. This also suggested that the charge carriers need not diffuse for long distances of the order of microns. Moreover, the proper contact of active photocatalysts on the fixed substrate enabled efficient mass transport of reactants, intermediates and products. Therefore, the solar hydrogen production activity values suggested that thin filmbased photocatalysts may lead to cost-effective hydrogen production since this protocol meets the requirements of a low amount of material and minimum equipment. With larger sized thin films (e.g., $\left.1 \mathrm{~m}^{2}\right)$, the effect was very likely to be more pronounced than that of the particulate form in solutions since the latter suffers from light absorption by the catalyst particles, light scattering ${ }^{24}$ rather than absorption, etc. We could provide a proof of concept that at least 11-12 times higher activity is feasible by minimizing the amount of material (from $25 \mathrm{mg}$ powder to $1 \mathrm{mg}$ thin film) and maximizing the light absorption by spreading over a large surface area. At a comparable amount ( $1 \mathrm{mg}$ ) of material, the thin film outperformed the powder form by a factor of 3 . We suggest more work on photocatalysis and water splitting with thin films, which is likely to produce better results than that of its powder counterpart. We also believe that the charge utilization aspects may be evaluated in the thin film form, such as life time measurements.

We also report the past efforts made using the photoelectrochemical (PEC) approach ${ }^{24-27}$ and artificial leaf ${ }^{28}$ conceptbased works reported with thin films prepared by different methods for water splitting under some applied potentials. Nonetheless, basic differences between PEC and photocatalysis do exist. However, we emphasize that compared to the irradiation of the particulate form of a photocatalyst under stirring conditions widely employed by many researchers around the globe for photocatalysis measurements, the present thin film approach described in the current manuscript is an attractive, simple and alternative proposal.

\section{Experimental details}

\section{Materials}

Potassium tetrachloropalladate $\left(\mathrm{K}_{2} \mathrm{PdCl}_{4}\right)$, titanium dioxide (P25), ascorbic acid (AA), polyvinylpyridine (PVP; 40 000), acetone, ethanol, methanol and $n$-hexane were procured from Sigma-Aldrich and used as received. For synthesis, cleaning and testing purposes, distilled de-ionized (DDI) water was used. 


\section{Synthesis of Pd nanoparticles}

The solution phase method was followed for the synthesis of 3$4 \mathrm{~nm}$ size Pd nanoparticles. ${ }^{29}$ In a $25 \mathrm{~mL}$ round-bottomed flask (RBF), $105 \mathrm{mg}$ of PVP and $60 \mathrm{mg}$ of AA were dissolved in $8 \mathrm{~mL}$ of DDI water under sonication and kept at $90{ }^{\circ} \mathrm{C}$ for $15 \mathrm{~min}$. Then, $60 \mathrm{mg}$ of $\mathrm{K}_{2} \mathrm{PdCl}_{4}$ was dissolved in $3 \mathrm{~mL}$ of water under sonication followed by the addition to the host solution at $90^{\circ} \mathrm{C}$. The reaction was continued for $3 \mathrm{~h}$. After the reaction, the solution was centrifuged and washed thoroughly with acetone and subsequently with an ethanol/hexane mixture to collect Pdnanoparticles. The Pd-nanoparticles were stored in ethanol for further use.

\section{Synthesis of $\mathbf{P d} / \mathbf{P 2 5}$ composite}

First, $1 \mathrm{wt} \%$ of Pd co-catalyst was loaded on titania (P25) by the dry impregnation method and employed for testing of $\mathrm{H}_{2}$ production activity. The desired amounts of P25 and Pd nanoparticles were taken in ethanol $(20 \mathrm{~mL})$ separately and sonicated for $15 \mathrm{~min}$. After sonication, the Pd nanoparticle solution was added to the P25 nanoparticle solution and sonicated for further $30 \mathrm{~min}$ for homogenous Pd dispersion on titania and dried at $60{ }^{\circ} \mathrm{C}$ for $12 \mathrm{~h}$.

\section{Preparation of photocatalyst thin films over glass plates}

Initially, the glass plates of different sizes $(1.25 \times 3.75,3.5 \times$ 3.75 , and $3.5 \times 7.5 \mathrm{~cm}^{2}$ ) were cleaned using soap solution, DI water and acetone under sonication for $45 \mathrm{~min}$ (each for $15 \mathrm{~min}$ ) in a sequential manner, kept at $65{ }^{\circ} \mathrm{C}$ for $3 \mathrm{~h}$ and used for thinfilm making. It should be noted that the quantification of hydrogen evolution was performed only for $1.25 \times 3.75 \mathrm{~cm}^{2}$ size film. The drop casting methodology was adopted to prepare the thin films of the photocatalyst over the glass plates without addition of any binders. In $1 \mathrm{~mL}$ of ethanol, $1 \mathrm{mg}$ of photocatalyst (P25 or Pd/P25) was added and sonicated for $30 \mathrm{~min}$ to obtain uniform dispersion of the catalyst. This catalyst dispersion was drop-casted repeatedly on the glass plate using $100 \mu \mathrm{L}$ micropipette and dried under ambient conditions for $12 \mathrm{~h}$.

\section{Characterization of thin films}

The physical properties of pristine (P25) and $\mathrm{Pd} / \mathrm{P} 25$ were explored by different characterization techniques. Powder X-ray diffraction (PXRD) data were collected using a PAN analytical X'pert Pro dual goniometer. $\mathrm{Cu} \mathrm{K} \alpha(1.5418 \AA$ A) radiation with a Ni filter was employed as the radiation source. The transmission electron microscopy (TEM) images of materials were recorded using an FEI TECNAI 3010 electron microscope operating at 200 $\mathrm{kV}$ and the images obtained were analysed using the Image software. Photoluminescence (PL) measurements were conducted using a Horiba Jobin Yuon Fluorolog 3 spectrophotometer equipped with a $450 \mathrm{~W}$ xenon lamp with a tunable excitation wavelength. All PL measurements were taken at excitation pulse of $310 \mathrm{~nm}$. The light absorption property was explored using a Shimadzu spectrometer (model UV-2550) with spectral-grade $\mathrm{BaSO}_{4}$ as the reference material. The morphological, composition, and thickness details of the prepared films over glass plate were obtained using a Quanta 200 3D field emission scanning electron microscope (FESEM).

\section{Testing of the photocatalysts}

All photocatalysis experiments were carried out in direct sunlight between 10 am and $4 \mathrm{pm}$ on the terrace of our laboratory premises. The GPS location of Pune, India, is 18.5204/ 73.8567/N $1831^{\prime} 14^{\prime \prime} / \mathrm{E} 7351^{\prime} 24^{\prime \prime}$. Before measurement, the power of illuminated solar irradiance was measured using a reference silicon solar cell and a read-out meter for every hour of reaction, and we considered the average of the values for calculation; it was $50.2 \mathrm{~mW} \mathrm{~cm}^{-2}$. Powder and thin film forms of photocatalysts were subjected to solar hydrogen generation with $25 \% \mathrm{v} / \mathrm{v}$ aqueous methanol solution. ${ }^{10}$ In $70 \mathrm{~mL}$ quartz RBF, $25 \mathrm{mg}$ powder catalyst was taken in $40 \mathrm{~mL}$ aqueous methanol and de-aerated with nitrogen for $30 \mathrm{~min}$. This was followed by sonication for 15 min to obtain a uniform dispersion of the catalyst and RBF was closed with an air-tight septum. The same procedure was adopted for thin film catalysts. For reliable comparison of the $\mathrm{H}_{2}$ production activities, $1 \mathrm{mg}$ of powder catalyst was also tested by the same procedure; it is to be noted that $1 \mathrm{mg}$ of catalyst was coated onto the $1.25 \times 3.75 \mathrm{~cm}^{2}$ glass substrate. The collected gas samples were analyzed periodically with an Agilent 7890A gas chromatograph (GC) equipped with a thermal conductivity detector at $200{ }^{\circ} \mathrm{C}$. The apparent quantum yield of solar hydrogen for all the catalysts was calculated by using the following equation: ${ }^{30}$

$$
\text { AQY }(\%)=\frac{2 \times \text { number of hydrogen molecules }}{\text { number of incident photons }} \times 100
$$

The number of incident photons was found to be $4 \%$ under natural sunlight, and the amount was calculated to be $3.6 \times$ $10^{18}$ photons per $\mathrm{s}$ from the contribution of up to $\sim 410 \mathrm{~nm}$; the light absorption by $\mathrm{P} 25$ and $\mathrm{Pd} / \mathrm{P} 25$ was considered up to $\sim 410 \mathrm{~nm}$ due to marginal visible-light absorption by rutilephase titania.

\section{Conflicts of interest}

The authors declare no competing financial interest.

\section{Acknowledgements}

$\mathrm{N}$. N acknowledges the SERB-DST for providing National postdoc fellowship (file no. PDF/2016/001999) and C. S. G. acknowledges the financial support from CSIR, New Delhi through MLP034526 project.

\section{References}

1 M. Bowker, Green Chem., 2011, 13, 2235.

2 A. A. Melvin, K. Illath, T. Das, T. Raja, S. Bhattacharyya and C. S. Gopinath, Nanoscale, 2015, 7, 13477-13488.

3 R. L. House, N. Y. M. Iha, R. L. Coppo, L. Alibabaei, B. D. Sherman, P. Kang, M. K. Brennaman, P. G. Hoertz and T. J. Meyer, J. Photochem. Photobiol., C, 2015, 25, 32-45. 
4 X. Zou and Y. Zhang, Chem. Soc. Rev., 2015, 44, 5148-5180.

5 (a) S. Rajaambal, M. Mapa and C. S. Gopinath, Dalton Trans., 2014, 43, 12546-12554; (b) S. Rajaambal, K. Sivaranjani and C. S. Gopinath, J. Chem. Soc., 2015, 127, 33-47.

6 P. A. Bharad, K. Sivaranjani and C. S. Gopinath, Nanoscale, 2015, 7, 11206-11215.

7 (a) P. Devaraji and C. S. Gopinath, Int. J. Hydrogen Energy, 2018, 43, 601-613; (b) P. Devaraji, N. K. Sathu and C. S. Gopinath, ACS Catal., 2014, 4, 2844-2853.

8 (a) S. Velu, N. Satoh, C. S. Gopinath and K. Suzuki, Catal. Lett., 2002, 82, 145-152; (b) V. Subramanian, E. S. Gnanakumar, D.-W. Jeong, W.-B. Han, C. S. Gopinath and H.-S. Roh, Chem. Commun., 2013, 49, 11257-11259.

9 M. R. Shaner, H. A. Atwater, N. S. Lewis and E. W. McFarland, Energy Environ. Sci., 2016, 9, 2354-2371.

10 (a) K. K. Patra and C. S. Gopinath, J. Phys. Chem. C, 2018, 122, 1206-1214; (b) K. K. Patra and C. S. Gopinath, ChemCatChem, 2016, 8, 3294-3301; (c) K. Sivaranjani, S. Rajaambal, T. Das, K. Roy, S. Bhattacharyya and C. S. Gopinath, ChemCatChem, 2014, 6, 522-530.

11 (a) K. K. Patra, B. D. Bhuskute and C. S. Gopinath, Sci. Rep., 2017, 7, 6516; (b) K. K. Patra, P. A. Bharad, V. Jain and C. S. Gopinath, J. Mater. Chem. A, 2019, 7, 3179-3189.

12 B. Liu, X.-B. Li, Y.-J. Gao, Z.-J. Li, Q.-Y. Meng, C.-H. Tung and L.-Z. Wu, Energy Environ. Sci., 2015, 8, 1443-1449.

13 P. Sudhagar, T. Song, A. Devadoss, J. W. Lee, M. Haro, C. Terashima, V. V. Lysak, J. Bisquert, A. Fujishima, S. Gimenez and U. Paik, Phys. Chem. Chem. Phys., 2015, 17, 19371-19378.

14 K. Maeda, M. Higashi, D. Lu, R. Abe and K. Domen, J. Am. Chem. Soc., 2010, 132, 5858-5868.

15 (a) A. A. Melvin, P. A. Bharad, K. Illath, M. P. Lawrence and C. S. Gopinath, ChemistrySelect, 2016, 5, 917-923; (b) K. Sivaranjani and C. S. Gopinath, J. Mater. Chem., 2011, 21, 2639-2647.

16 A. Xiong, G. Ma, K. Maeda, T. Takata, T. Hisatomi, T. Setoyama, J. Kubota and K. Domen, Catal. Sci. Technol., 2014, 4, 325-328.
17 M. Schröder, K. Kailasam, J. Borgmeyer, M. Neumann, A. Thomas, R. Schoemäcker and M. Schwarze, Energy Technol., 2015, 3, 1014-1017.

18 Y. Goto, T. Hisatomi, Q. Wang, T. Higashi, K. Ishikiriyama, T. Maeda, Y. Sakata, S. Okunaka, H. Tokudome, M. Katayama, S. Akiyama, H. Nishiyama, Y. Inoue, T. Takewaki, T. Setoyama, T. Minegishi, T. Takata, T. Yamada and K. Domen, Joule, 2018, 2, 509-520.

19 K. Sivaranjani, S. Agarkar, S. B. Ogale and C. S. Gopinath, J. Phys. Chem. C, 2012, 116, 2581-2587.

20 B. Xi, L. K. Verma, J. Li, C. S. Bhatia, A. J. Danner, H. Yang and H. C. Zeng, ACS Appl. Mater. Interfaces, 2012, 4, 10931102.

21 F. Gao, Y. Wang, D. Shi, J. Zhang, M. Wang, X. Jing, R. H. Baker, P. Wang, S. M. Zakeeruddin and M. Grätzel, J. Am. Chem. Soc., 2008, 130, 10720-10728.

22 K. Hashimoto, H. Irie and A. Fujishima, Jpn. J. Appl. Phys., 2005, 44, 8269-8285.

23 N. Nalajala, A. Chakraborthy, B. Bera and M. Neergat, Nanotechnology, 2016, 27, 065603.

24 F. E. Osterloh, Chem. Soc. Rev., 2013, 42, 2294-2320.

25 A. Fujishima and K. Honda, Nature, 1972, 238, 37-38.

26 S. Kment, F. Riboni, S. Pausova, L. Wang, L. Wang, H. Han, Z. Hubicka, J. Krysa, P. Schmuki and R. Zboril, Chem. Soc. Rev., 2017, 46, 3716-3769.

27 (a) T. J. Jacobsson, V. Fjallstrom, M. Edoff and T. Edvinsson, Energy Environ. Sci., 2014, 7, 2056-2070; (b) S. Licht, B. Wang, S. Mukerji, T. Soga, M. Umeno and H. Tributsch, J. Phys. Chem. B, 2000, 104, 8920-8924.

28 D. G. Nocera, Acc. Chem. Res., 2012, 45, 767-776.

29 N. Heston, Newport Oriel, AM1.5 Solar Simulator User Manual, http://www.mccl.chem.ufl.edu/sec/manual/

User_Manual_MCCL_AM1.5_Solar_Simulator.docx.

30 Y. Rong, Y. Ming, W. Ji, D. Li, A. Mei, Y. Hu and H. Han, J. Phys. Chem. Lett., 2018, 9, 2707-2713. 